\title{
A COMPUTATIONAL STUDY ON THE HYDROGEN-BONDED COMPLEXES FORMED BY THE ANTHYRIDONE AND DIALDEHYDE DERIVATIVES
}

\author{
Xiaopeng Chen, Qiwen Teng ${ }^{*}$, Shi Wu and Lingjia Xu
}

Department of Chemistry, Zhejiang University, Hangzhou, Zhejiang 310027, China

\author{
(Received May 22, 2006; revised July 13, 2006)
}

\begin{abstract}
A theoretical study on hydrogen-bonded complex 1 formed by anthyridone (monomer A) and 2,6-diaminopyridine-3,5-dialdehyde (monomer B) was performed using the AM1 method to obtain its binding energy. A series of complexes $\mathbf{2}$ to $\mathbf{9}$ were designed by changing the R-groups on monomer A in complex 1 into $\mathrm{C}_{6} \mathrm{H}_{5}$, $p$-toluene, $p$-phenol, $\mathrm{OH}, \mathrm{OCH}_{3}$, and turning the X-groups on monomer $\mathrm{B}$ into $\mathrm{F}, \mathrm{Cl}$, I, respectively. Based on the optimized geometries, the electronic spectra for the complexes were calculated with the INDO/CIS method and the IR spectra were computed utilizing the AM1 method. It was indicated that the dimer could be formed by the two monomers via triple hydrogen bonds because of its negative binding energy. The binding energies of the complexes were changed with the change of the electronic properties and steric effects of the substituents on the monomers. The first absorptions in the electronic spectra of the complexes were red-shifted compared with those of the monomers. The stretching vibrations of the N-H bonds on the monomers were weakened and their frequencies were reduced with the formation of the hydrogen bonds.
\end{abstract}

KEY WORDS: Anthyridone, 2,6-Diaminopyridine-3,5-dialdehyde, Hydrogen bonding, IR spectra, AM1

\section{INTRODUCTION}

With the development in studies on triply hydrogen-bonded systems, more and more complexes are used to synthesize new polymers and identify small molecules [1-6]. Zerkowski et al. [1] studied the D-ADA (D: donor, A: acceptor) triple hydrogen bonding between barbituric acid and melamine, which were used as the monomers to form the two-dimensional polymer. Suarez et al. [2] employed the two diastereomers formed by piperidinedione and pyrimidine ramification to obtain a pair of chiral enantiomers, which were the dimers with DAD-ADA hydrogen bonds. Hamilton et al. [3] prepared the macromolecular ring with pyrimidine and naphthaline, and determined the structures of the ring and triple hydrogen-bonded system with the ${ }^{1} \mathrm{H}$ NMR and $\mathrm{X}$-ray diffraction experiments. This macromolecular ring was used to identify thymine via the hydrogen bonds. Schmittd et al. [4] investigated the hydrogen-bonded cluster generated by tryptamine and $\mathrm{H}_{2} \mathrm{O}$ using the Hartree-Fock method with the 6-31G(d, p) basis set, and computed the vibration spectra for the different structures of tryptamine. Manesiotis et al. [5] measured the infrared spectra, ${ }^{1} \mathrm{H}$ NMR and fluorescent spectra for the two pyrimidine derivatives and explored the triply hydrogen-bonded dimer between them. Since there are three forms of the triple hydrogen bonds, Murray et al. [6] synthesized the different kinds of the triple hydrogen-bonded complexes produced by the anthyridone and dialdehyde derivatives, and determined their stability constants and ${ }^{1} \mathrm{H}$ NMR spectra. Based on this background, the structures and spectra of the triply hydrogen-bonded complexes formed between anthyridone and 2,6-diaminopyridine-3,5-dialdehyde were investigated with the AM1 and INDO/CIS methods. Then the effects of the different substituents on the binding energy were explored, and the potential curves of the proton transfer in the complex were predicted.

*Corresponding author. E-mail: wushi@zju.edu.cn 


\section{THEORETICAL}

The binding energy of a complex was defined as the total energy of the complex minus the energies of the two independent monomers [7-13]. The triply hydrogen-bonded dimer (complex 1: $\mathrm{R}=\mathrm{H}, \mathrm{X}=\mathrm{H}$ ) was composed of anthyridone (monomer A) and 2, 6-diaminopyridine-3,5dialdehyde (monomer B). On the basis of complex 1, complexes 2, 3, 4, 5 and 6 were designed by changing the R-groups on monomer $\mathrm{A}$ into $\mathrm{C}_{6} \mathrm{H}_{5}, p$-toluene, $p$-phenol, $\mathrm{OH}$ and $\mathrm{OCH}_{3}$, respectively, shown in Figure 1. Then complexes 7, 8 and 9 were formed by changing the Xgroups on monomer B in complex 1 with $\mathrm{F}, \mathrm{Cl}$ and $\mathrm{I}$, respectively. After that, the geometries of the complexes were optimized employing the AM1 method [14] in the GAUSSIAN 03 program [15] to accomplish the binding energies. Based on the optimized geometries, the electronic spectra of the complexes were computed using the INDO/CIS method [16-22] to obtain absorption wavelengths $\lambda$ and oscillator strength $f$. In the calculation performed, 197 configurations including the ground state were states generated by exciting electrons from the 14 highest occupied molecular orbitals (HOMO) into the 14 lowest unoccupied molecular orbitals (LUMO). Finally, the IR spectra of the complexes and the potential curves for the proton transfer in complex 1 were calculated with the AM1 method.

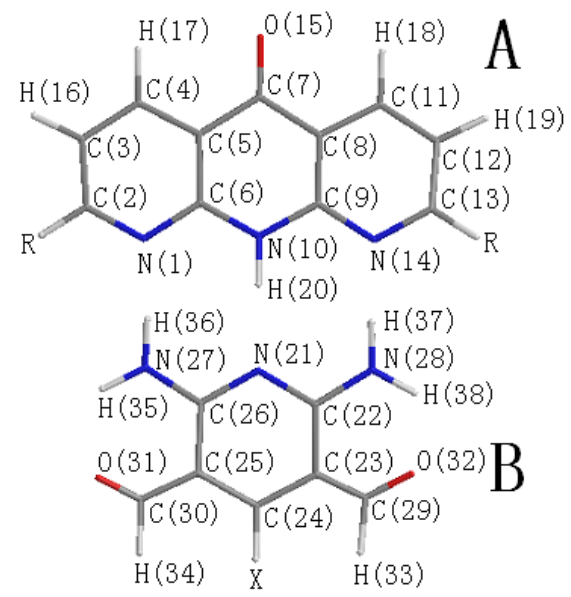

Complex 1: $\mathrm{R}=\mathrm{H}, \mathrm{X}=\mathrm{H}$; Complex 2: $\mathrm{R}=\mathrm{C}_{6} \mathrm{H}_{5}, \mathrm{X}=\mathrm{H}$; Complex 3: $\mathrm{R}=$ p-toluene, $\mathrm{X}=\mathrm{H}$; Complex 4: $\mathrm{R}=$ p-phenol, $\mathrm{X}=\mathrm{H}$; Complex 5: $\mathrm{R}=\mathrm{OH}, \mathrm{X}=\mathrm{H}$; Complex 6: $\mathrm{R}=\mathrm{OCH}_{3}, \mathrm{X}=\mathrm{H}$; Complex 7: R = H, X = F; Complex 8: $\mathrm{R}=\mathrm{H}, \mathrm{X}=\mathrm{Cl}$; Complex 9: $\mathrm{R}=\mathrm{H}, \mathrm{X}=\mathrm{I}$.

Figure 1. The optimized geometries of the hydrogen bonding complexes.

\section{RESULTS AND DISCUSSION}

The structures and stabilities of the complexes

The binding energies of complexes $\mathbf{1}$ - $\mathbf{9}$ are given in Table 1. The lengths of the hydrogen bonds in complexes $\mathbf{1}$ to $\mathbf{9}$ were different with the change of chemical environment in the monomers. In complex 1, the lengths of hydrogen bonds $H(36) \ldots N(1), H(20) \ldots N(21)$, 
$\mathrm{H}(37) \ldots \mathrm{N}(14)$ were $0.2693,0.2532$ and $0.2572 \mathrm{~nm}$, in agreement with the bond length of $\mathrm{N} \ldots \mathrm{H}$ (0.2484 nm [4]). Thus complex 1 was formed by the hydrogen bonding between monomers A and B. It was reported that the basis set superposition error (BSSE) for most hydrogen-bonded complexes was smaller than $10 \mathrm{~kJ} \cdot \mathrm{mol}^{-1}$ [7], and BSSE for the binding energy of the hydrogenbonded complex formed by melamine and cyclotrione calculated by B3LYP/STO-3G, 3-21G and $6-31 \mathrm{G}(\mathrm{d})$ methods were $1.7350,0.0675$ and $0.4820 \mathrm{~kJ} \cdot \mathrm{mol}^{-1}$ [8]. Here BSSE for the binding energy of complex 1, calculated by the B3LYP/STO-3G, 3-21G and 6-31G methods, were $0.0096,0.0096$ and $0.0386 \mathrm{~kJ} \cdot \mathrm{mol}^{-1}$, respectively, which were very small. While the R-groups on monomer A were replaced by the aromatic groups, the binding energies of complexes $\mathbf{2}$ to 4 were smaller than that of complex 1. This was because the aromatic groups possessed large steric effects, which was unfavorable to the formation of the hydrogen bonding. On the other hand, the augmentation in the electron-donating abilities of the benzene, toluene and phenol groups led to the elevation of the binding energies since the electron density on the $\mathrm{N}$ (1) and $\mathrm{N}$ (14) atoms, favorable to the hydrogen bonds, was enhanced. However, the binding energies of complexes 5 and $\mathbf{6}$ were larger than that of complex 1. This indicated that the electron-donating effect rather than the steric effect played important role in the formation of hydrogen bonding when the R-groups were the small hydroxy or methoxy groups, which was consistent with the calculations [23, 24]. Likewise, the binding energies of complexes 7 to 9 were shrunk, in turn, for the F-, Cl- and I-groups on monomer B owned the less and less electron-withdrawing abilities, resulting in the more and more electron density on the $\mathrm{H}(36)$ and $\mathrm{H}(37)$ atoms on the $-\mathrm{NH}_{2}$ groups located at the meta position of the halogen atoms.

Table 1. The binding energies of the complexes.

\begin{tabular}{|c|c|c|c|c|c|c|c|c|c|}
\hline Complexes & 1 & 2 & 3 & 4 & 5 & 6 & 7 & 8 & 9 \\
\hline $\begin{array}{l}\text { Binding energies } \\
\mathrm{kJ} \cdot \mathrm{mol}^{-1}\end{array}$ & -11.9428 & -9.7451 & -9.8319 & -11.8368 & -17.2347 & -17.7166 & -13.2827 & -9.7740 & -1.2916 \\
\hline
\end{tabular}

\section{The electronic structures at the ground state}

The LUMO-HOMO energy gaps of complexes $\mathbf{1}-\mathbf{9}$ are shown in Figure 2. The HOMO and LUMO energies of complex 1 were -8.819 and $-0.928 \mathrm{eV}$, and the energy gap was $7.891 \mathrm{eV}$, less than those of monomers $\mathrm{A}$ and $\mathrm{B}(8.163$ and $8.513 \mathrm{eV})$. This was because the hydrogen bonds between monomers $\mathrm{A}$ and $\mathrm{B}$ had changed the electronic property of complex $\mathbf{1}$ to a certain extent, raising the HOMO energy and lessening the LUMO energy. The energy gaps of complexes 2 to $\mathbf{6}$ were diminished obviously, whereas those of complexes 7 to $\mathbf{9}$ with the electron-withdrawing groups on monomer $\mathrm{B}$ were fortified, relative to that of complex $\mathbf{1}$. The dipole moment of complex 1 was $0.9906 \times 10^{-30} \mathrm{C} \cdot \mathrm{m}$, smaller than those of monomers A and B $\left(2.3815 \times 10^{-30}\right.$ and $\left.1.7345 \times 10^{-30} \mathrm{C} \cdot \mathrm{m}\right)$, illustrating that the dipole moment of monomer $\mathrm{A}$ somewhat counteracted that of monomer B via triple N...H hydrogen bonds in complex $\mathbf{1}$. Besides, the net charges of monomers $\mathrm{A}$ and $\mathrm{B}$ were 0.0003 and -0.0003 , so the electrons were transferred from monomer A to monomer B in complex 1. The net charges of the $\mathrm{N}$ (14) atoms in complex 2 and $\mathbf{3}$ were -0.2118 and -0.2131 , agreeing with the increasing electron-donating abilities of the $-\mathrm{C}_{6} \mathrm{H}_{5}$ and $-\mathrm{C}_{6} \mathrm{H}_{4} \mathrm{CH}_{3}$ groups on monomer A. Analogously, the transfer of electrons was aggrandized when the $\mathrm{X}$-groups on monomer $\mathrm{B}$ were those with more and more electron-withdrawing abilities. 


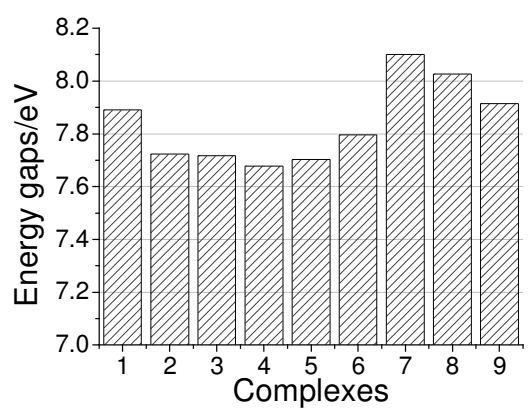

Figure 2. The LUMO-HOMO energy gaps of the complexes.

\section{The electronic absorption spectra}

The strong absorption peaks for monomer A appeared at 215.6, 240.8 and $288.2 \mathrm{~nm}$, compatible with the experimental data [4]. The strong absorption peaks of monomer B were located at 232.8, 255.1 and $329.4 \mathrm{~nm}$. All of the above absorptions could be found in the electronic spectrum of complex $\mathbf{1}$. The first absorption band at $389.9 \mathrm{~nm}$ of complex $\mathbf{1}$ was produced by the electronic transition from HOMO $a_{2}(67)$ to LUMO $b_{1}(68)$, which was symmetry-forbidden, thus oscillator strength was 0 . The second peak at $323.2 \mathrm{~nm}$ of complex 1 (Table 2) was generated by the symmetry-allowed electronic transition from $b_{1}(66)$ to $a_{1}(69)$. Compared with those of the monomers, the first absorption peaks for complexes $1,7,8$ and 9 were basically red-shifted, due to their less LUMO-HOMO energy gaps.

Table 2. The electronic spectra of complexes $\mathbf{1}, \mathbf{7}, \mathbf{8}$ and $\mathbf{9 .}$

\begin{tabular}{|c|c|c|c|c|c|c|c|}
\hline$\lambda(\mathrm{nm})$ & $f$ & Transition nature & Coefficient & $\lambda(\mathrm{nm})$ & $f$ & Transition nature & Coefficient \\
\hline \multicolumn{4}{|c|}{ Complex 1} & \multicolumn{4}{|c|}{ Complex 7} \\
\hline 323.2 & 0.3220 & $\mathrm{~b}_{1}(66) \rightarrow \mathrm{a}_{1}(69)$ & 0.9179 & 327.4 & 0.2958 & $\mathrm{~b}_{1}(69) \rightarrow \mathrm{a}_{1}(71)$ & 0.9192 \\
\hline 311.5 & 0.3453 & $a_{1}(67) \rightarrow b_{1}(68)$ & -0.8615 & 311.1 & 0.3066 & $a_{1}(70) \rightarrow a_{1}(72)$ & 0.8714 \\
\hline 302.5 & 0.2388 & $b_{1}(66) \rightarrow b_{1}(70)$ & 0.9561 & 298.1 & 0.2613 & $b_{1}(69) \rightarrow b_{1}(73)$ & -0.9649 \\
\hline 286.2 & 0.2732 & $a_{1}(67) \rightarrow b_{1}(72)$ & -0.5267 & 286.1 & 0.2691 & $a_{1}(70) \rightarrow b_{2}(74)$ & -0.5199 \\
\hline 277.3 & 0.0819 & $a_{1}(67) \rightarrow a_{1}(71)$ & -0.7683 & 276.8 & 0.0763 & $a_{1}(70) \rightarrow b_{2}(74)$ & 0.7584 \\
\hline 264.8 & 0.0152 & $a_{1}(58) \rightarrow b_{1}(68)$ & 0.5215 & 264.3 & 0.0143 & $a_{1}(61) \rightarrow a_{1}(72)$ & 0.5130 \\
\hline 256.7 & 0.0082 & $a_{1}(56) \rightarrow b_{2}(74)$ & 0.4682 & 258.5 & 0.0062 & $a_{1}(58) \rightarrow a_{1}(71)$ & -0.5186 \\
\hline 252.0 & 0.1574 & $b_{1}(66) \rightarrow b_{2}(74)$ & -0.5697 & 250.4 & 0.1142 & $a_{1}(58) \rightarrow b_{1}(73)$ & 0.5922 \\
\hline \multicolumn{4}{|c|}{ Complex 8} & \multicolumn{4}{|c|}{ Complex 9} \\
\hline 329.3 & 0.3281 & $\mathrm{a}_{1}(69) \rightarrow \mathrm{a}_{1}(71)$ & 0.9216 & 374.2 & 0.0010 & $a_{1}(64) \rightarrow b_{1}(71)$ & 0.4565 \\
\hline 311.1 & 0.3135 & $b_{1}(70) \rightarrow b_{1}(72)$ & 0.8679 & 328.7 & 0.3388 & $\mathrm{~b}_{2}(69) \rightarrow \mathrm{b}_{1}(71)$ & -0.9187 \\
\hline 299.9 & 0.2344 & $a_{1}(69) \rightarrow a_{1}(73)$ & -0.9568 & 313.6 & 0.2781 & $\mathrm{~b}_{2}(69) \rightarrow \mathrm{a}_{1}(73)$ & -0.6240 \\
\hline 286.0 & 0.2746 & $\mathrm{~b}_{1}(70) \rightarrow \mathrm{a}_{1}(74)$ & -0.5243 & 310.9 & 0.1060 & $\mathrm{~b}_{1}(70) \rightarrow \mathrm{a}_{1}(72)$ & 0.7536 \\
\hline 276.6 & 0.0707 & $b_{1}(70) \rightarrow a_{1}(74)$ & -0.7524 & 299.7 & 0.1630 & $b_{2}(69) \rightarrow a_{1}(73)$ & 0.7092 \\
\hline 274.3 & 0.0079 & $a_{1}(69) \rightarrow a_{1}(77)$ & -0.9812 & 286.3 & 0.2845 & $b_{1}(70) \rightarrow b_{1}(76)$ & -0.4768 \\
\hline 266.2 & 0.0116 & $a_{1}(61) \rightarrow b_{1}(72)$ & 0.5011 & 274.7 & 0.0382 & $\mathrm{a}_{1}(68) \rightarrow \mathrm{a}_{1}(72)$ & 0.5118 \\
\hline 263.3 & 0.0044 & $b_{1}(60) \rightarrow b_{1}(72)$ & 0.5080 & 273.2 & 0.0179 & $\mathrm{a}_{1}(60) \rightarrow \mathrm{a}_{1}(72)$ & -0.3414 \\
\hline
\end{tabular}


The first absorptions of complexes 2 to 6 (Figure 3) were red-shifted compared with that of complex 1 because their energy gaps were reduced by the electron-donating aromatic groups on monomer A. The main absorptions in the electronic spectra for complexes $\mathbf{5}$ and $\mathbf{6}$ were almost the same. So the effects of hydroxy and methoxy groups on absorptions of the complexes were unobvious.
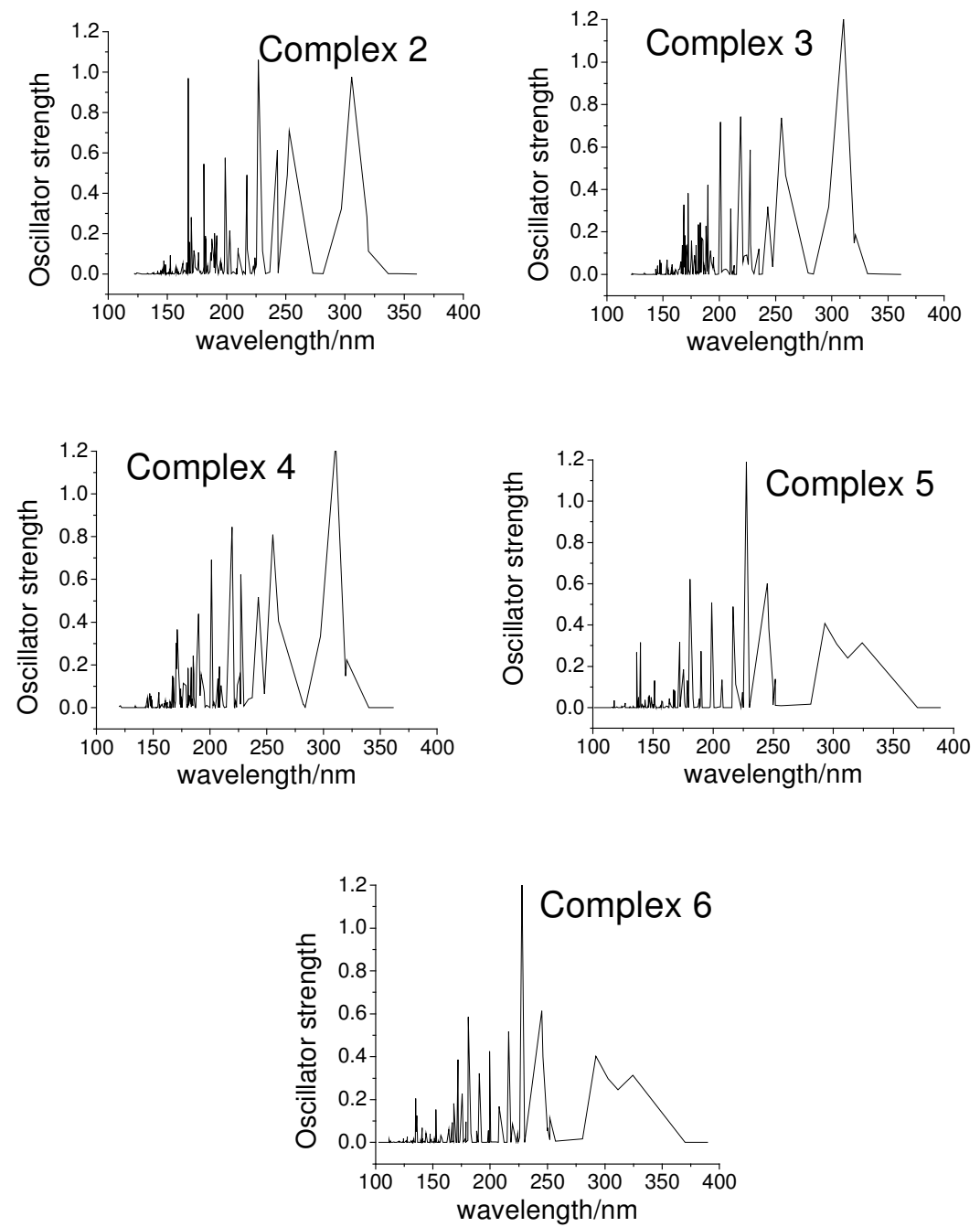

Figure 3. The electronic spectra of complexes 2-6.

\section{The IR spectra}

In the IR spectra of monomers $\mathrm{A}$ and $\mathrm{B}$, the stretching vibrations of the $\mathrm{N}-\mathrm{H}$ bonds appeared from 3030 to $3500 \mathrm{~cm}^{-1}$, and those of $\mathrm{C}=\mathrm{N}$ and $\mathrm{C}=\mathrm{O}$ were located between 1400 and $1800 \mathrm{~cm}^{-1}$, as well as those of $\mathrm{C}-\mathrm{H}$ on the aromatic rings were within the range of 400 to $800 \mathrm{~cm}^{-1}$, in 
agreement with the experiment [25]. In the IR spectrum of complex 1, the vibrations at the range of 2030 to $3070 \mathrm{~cm}^{-1}$ resembled those of monomer A, and the vibrations from 400 to $1600 \mathrm{~cm}^{-1}$ and 3070 to $3500 \mathrm{~cm}^{-1}$ were similar to the corresponding absorptions of monomer $\mathrm{B}$, whereas the frequencies in the region of 1600 to $2030 \mathrm{~cm}^{-1}$ were arisen from monomers $\mathrm{A}$ and $\mathrm{B}$. The $\mathrm{N}-\mathrm{H}$ stretching vibrations in monomers A, B and complex 1 were $3425,3458,3396 \mathrm{~cm}^{-1}$, respectively, demonstrating that the $\mathrm{N}-\mathrm{H}$ stretching vibrations were decreased and their frequencies became less with the formation of the hydrogen bonding in complex $\mathbf{1}$. Also, the $\mathrm{N}-\mathrm{H}$ stretching vibrations in the IR spectra of complexes $\mathbf{2}$ to $\mathbf{6}$ were impaired relative to those of monomers (Figure 4), which were caused by the hydrogen bonding. There existed several strong bands in the area of 1600 to $2000 \mathrm{~cm}^{-1}$ for complexes $\mathbf{4}, 5$ and $\mathbf{6}$, which could be employed to distinguish the different complexes.
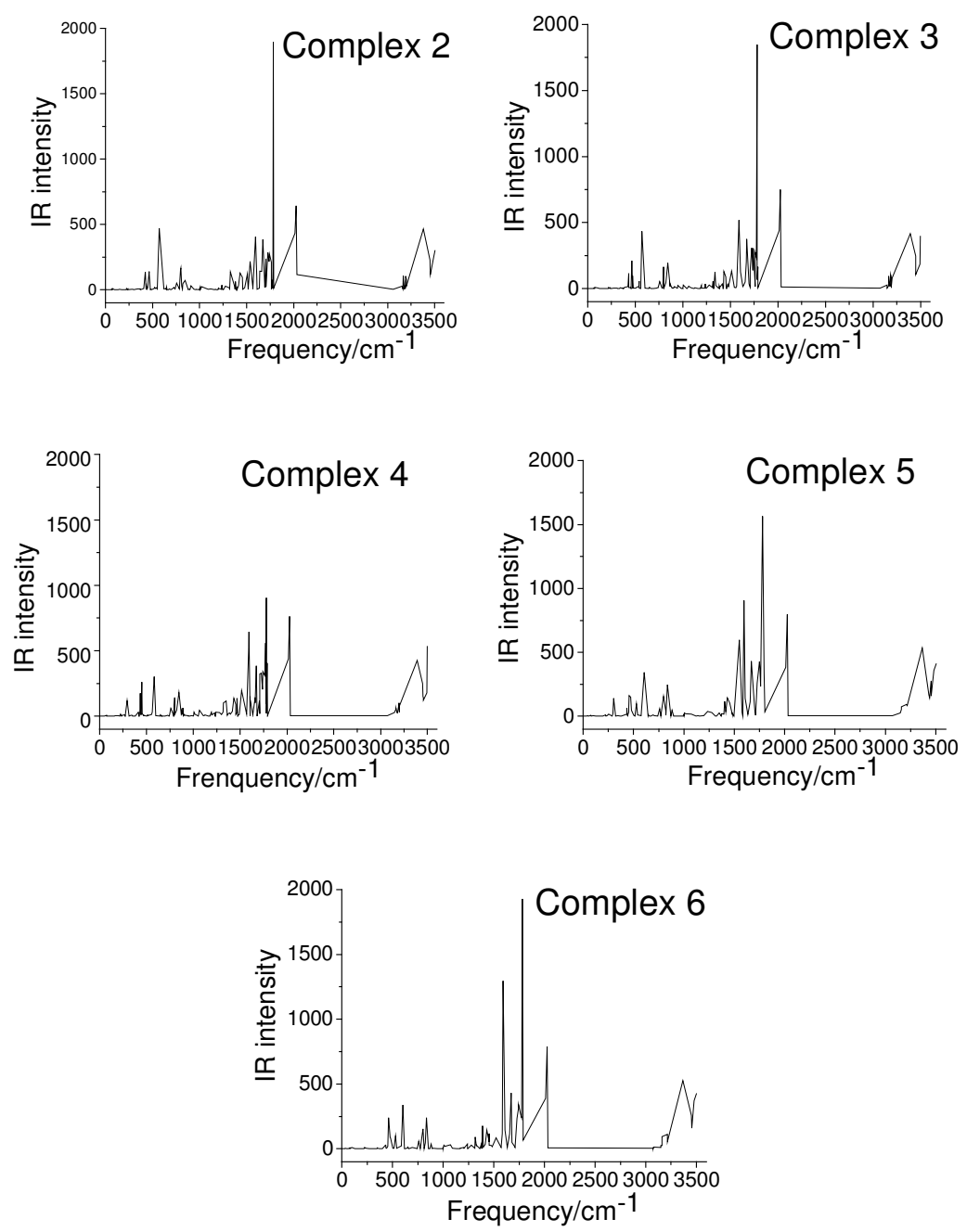

Figure 4. The IR spectra of complexes 2-6. 


\section{The potential curves}

If the three bond lengths $\mathrm{d}_{\mathrm{N}(27)-\mathrm{H}(36)}, \mathrm{d}_{\mathrm{N}(10)-\mathrm{H}(20)}$ and $\mathrm{d}_{\mathrm{N}(28)-\mathrm{H}(37)}$ of the $\mathrm{N}(27)-\mathrm{H}(36), \mathrm{N}(10)-\mathrm{H}(20)$ and $\mathrm{N}(28)-\mathrm{H}(37)$ bonds in complex 1 were all fixed at $0.11,0.12, \ldots, 0.21 \mathrm{~nm}$, respectively, other coordinates including bond lengths, bond angles and dihedral angles were optimized [810] by the AM1 method [14] to gain the total energy for the system at the ground state. After that, the electronic spectrum was calculated to obtain the lowest transition energy thus to find the total energy at the first excited state. Then the potential curves for the proton transfer at the ground state and excited state were actualized in Figure 5. The bond length of N(27)-H(36) was $0.193 \mathrm{~nm}$ at the transition state. The activation energies for the forward and backward reactions were 2.71 and $0.36 \mathrm{eV}$ at the ground state, and those were 2.20 and $0.54 \mathrm{eV}$ at the excited state. Since the reverse activation energies at the ground state and excited state were both small, the isomer of complex $\mathbf{1}$ could be easily changed into the regular one; thereby complex $\mathbf{1}$ was the most stable structure.

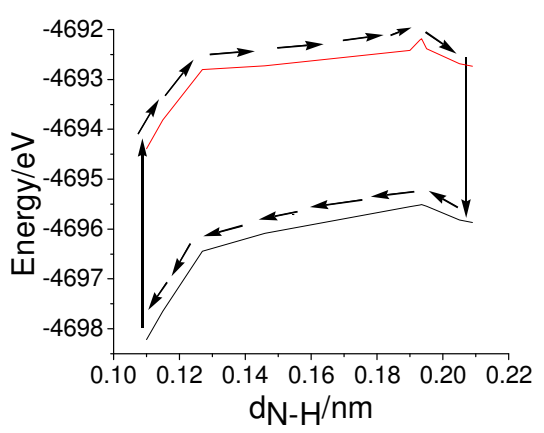

Figure 5. The potential curves for the proton transfer.

As stated above, the complex could be formed by monomers A and B via the DAD-ADA triple hydrogen bonds. There were certain influences of substituents at different positions on the stabilities of the complexes. These complexes were stabilized by the electron-donating groups on monomer A and the electron-withdrawing groups on monomer B, while the R-groups with the large steric effects were disadvantageous to the formation of the complexes. The LUMOHOMO energy gaps of the complexes were affected by the electronic properties rather than the steric effects of the substituents. The first absorption peaks in the electronic spectra for the complexes were red-shifted relative to those of the monomers. The $\mathrm{N}-\mathrm{H}$ stretching vibrations on the monomers were weakened with the formation of the hydrogen bonding. It was proven from the curves of the proton transfer that complex $\mathbf{1}$ was the stable structure formed by monomers $\mathrm{A}$ and $\mathrm{B}$.

\section{REFERENCES}

1. Zerkowski, J.A.; Seto, C.T.; Wierda, D.A.; Whitesides, G.M. J. Am. Chem. Soc. 1990, 112, 9025.

2. Suarez, M.; Branda, N.; Lehn, J.M.; Decian, A.; Fiischer, J. Helv. Chim. Acta 1998, 81, 1.

3. Hamilton, A.D.; Engen, D.V. J. Am. Chem. Soc. 1987, 109, 5036.

4. Schmitt, M.; Bohm, M.; Ratzer, C.; Vu, C.; Kalkman, I.; Meerts, W.L. J. Am. Chem. Soc. 2005, 127, 10356. 
5. Manesiotis, P.; Hall, A.J.; Sellergren, B. J. Org. Chem. 2005, 70, 2729.

6. Murray, T.J.; Zimmerman, S.C. J. Am. Chem. Soc. 1992, 114, 4011.

7. Zhou, X.M.; Zhou, Z.Y.; Fu, H.; Shi, Y.; Zhang, H. J. Mol. Stru.: Theochem 2005, 714, 7.

8. Zhu, L.; Teng, Q.; Wu, S. Chin. J. Struct. Chem. 2006, 25, 143.

9. Teng, Q.; Wu, S.; Chen, S.; Zhang, Y.; Zheng, X. Chem. J. Chin. Univ. 2002, 23, 1331.

10. Wu, S.; Teng, Q.; Chen, X.; Zhou, R. Chem. J. Chin. Univ. 2003, 24, 1271.

11. Qi, L.; Teng, Q.; Wu, S.; Liu, Z. Chem. J. Chin. Univ. 2005, 26, 1909.

12. Qi, L.; Teng, Q.; Wu, S.; Liu, Z. Chin. J. Struct. Chem. 2005, 24, 537.

13. Jin, H.; Feng, J.; Ren, A.; Li, Z.; Wang, Z.; Zhang, X. Acta Chim. Sinica. 2000, 58, 194.

14. Dewar, M.J.S.; Zoebisch, E.G.; Healy E.F.; Stewart, J.J.P. J. Am. Chem. Soc. 1985, 107 , 3902.

15. Frisch, M. J.; Trucks, G.W.; Schlegel, H.B.; Scuseria, G.E.; Robb, M.A.; Cheeseman, J.R.; Montgomery, J.A.; Vreven, Jr. T.; Kudin, K.N.; Burant, J.C.; Millam, J.M.; Iyengar, S.S.; Tomasi, J.; Barone, V.; Mennucci, B.; Cossi, M.; Scalmani, G.; Rega, N.; Petersson, G.A.; Nakatsuji, H.; Hada, M.; Ehara, M.; Toyota, K.; Fukuda, R.; Hasegawa, J.; Ishida, M.; Nakajima, T.; Honda, Y.; Kitao, O.; Nakai, H.; Klene, M.; Li, X.; Knox, J.E.; Hratchian, H. P.; Cross, J.B.; Adamo, C.; Jaramillo, J.; Gomperts, R.; Stratmann, R.E.; Yazyev, O.; Austin, A.J.; Cammi, R.; Pomelli, C.; Ochterski, J.W.; Ayala, P.Y.; Morokuma, K.; Voth, G.A.; Salvador, P.; Dannenberg, J.J.; Zakrzewski, V.G.; Dapprich, S.; Daniels, A.D.; Strain, M.C.; Farkas, O.; Malick, D.K.; Rabuck, A.D.; Raghavachari, K.; Foresman, J.B.; Ortiz, J.V.; Cui, Q.; Baboul, A.G.; Clifford, S.; Cioslowski, J.; Stefanov, B.B.; Liu, G.; Liashenko, A.; Piskorz, P.; Komaromi, I.; Martin, R.L.; Fox, D.J.; Keith, T.; Al-Laham, M.A.; Peng, C.Y.; Nanayakkara, A.; Challacombe, M.; Gill, P.M.W.; Johnson, B.; Chen, W.; Wong, M.W.; Gonzalez, C.; Pople, J.A. Gaussian 03, Revision B. 01, Gaussian Inc.: Pittsburgh, PA; 2003.

16. Ridley, J.; Zerner, M.C. Theoret. Chim. Acta 1973, 32, 111.

17. Teng, Q.; Wu, S. Chem. J. Chin. Univ. 2001, 22, 1019.

18. Wu, S.; Teng, Q. Chem. J. Chin. Univ. 2002, 23, 132.

19. Teng, Q.; Wu, S.; Zhu, Z. Int. J. Quantum Chem. 2003, 91, 39.

20. Teng, Q.; Wu, S. J. Mol. Stru.: Theochem 2005, 719, 47.

21. Teng, Q.; Wu, S. Int. J. Quantum Chem. 2005, 104, 279.

22. Teng, Q.; Wu, S. J. Mol. Stru.: Theochem 2005, 756, 103.

23. Zhou, Y.; Zhao, X.; Li, Z.; Chen, G.; Liu, R. Acta Chim. Sinica. 2003, 61, 963.

24. Wang, C.; Qi, X.; Ma, Y.; Yang, Z. Chem. J. Chin. Univ. 2004, 25, 1111.

25. Caluwe, P.; Majewicz, T.G.J. Org. Chem. 1977, 42, 3410. 